\title{
The Degree of the Predischarge Pulmonary Congestion in Patients Hospitalized for Worsening Heart Failure Predicts Readmission and Mortality
}

\author{
Michael Kleiner-Shochat ${ }^{a, b}$ Daniel Kapustin ${ }^{c} \quad$ Marat Fudim $^{d}$ \\ Andrew P. Ambrosye, Juliya Glantz ${ }^{a, b}$ Mark Kazatsker ${ }^{a, b}$ Ilia Kleinerg \\ Jean Marc Weinsteing ${ }^{g}$ Gurusher Panjrath ${ }^{\mathrm{h}}$ Ariel Roguin ${ }^{\mathrm{a}, \mathrm{b}}$ \\ Simcha R. Meisel ${ }^{a}$ b

\begin{abstract}
${ }^{a}$ Heart Institute, Hillel Yaffe Medical Center, Hadera, Israel; ${ }^{b}$ The Ruth and Bruce Rappaport Faculty of Medicine, Technion, Haifa, Israel; ' University of Toronto Faculty of Medicine, Toronto, ON, Canada; ${ }^{\mathrm{d}}$ Department of Cardiology, Duke University Medical Center, Durham, NC, USA; ${ }^{\mathrm{T}}$ The Permanente Medical Group, San Francisco, CA, USA; ${ }^{\mathrm{f}}$ Division of Research, Kaiser Permanente Northern California, Oakland, CA, USA; ${ }^{9}$ Department of Cardiology, University Medical Center, Beer Sheva, Israel; ${ }^{\text {h}}$ Department of Medicine (Cardiology), George Washington University School of Medicine and Health Sciences, Washington, DC, USA
\end{abstract}

\section{Keywords}

Heart failure $\cdot$ Lung impedance $\cdot$ NT-proBNP level .

Readmission $\cdot$ Residual pulmonary congestion

\begin{abstract}
Background: Prediction of readmission and death after hospitalization for heart failure (HF) is an unmet need. Aim: We evaluated the ability of clinical parameters, NT-proBNP level and noninvasive lung impedance (LI), to predict time to readmission (TTR) and time to death (TTD). Methods and Results: The present study is a post hoc analysis of the IMPEDANCE-HF extended trial comprising 290 patients with LVEF $\leq 45 \%$ and New York Heart Association functional class II-IV, randomized 1:1 to LI-guided or conventional therapy. Of all patients, 206 were admitted 766 times for HF during a follow-up of $57 \pm 39$ months. The normal LI (NLI), representing the "dry" lung status, was calculated for each patient at study entry. The current degree of pulmonary congestion (PC) compared with its dry status was represented by $\Delta L I R=$
\end{abstract}

([measured LI/NLI] - 1) $\times 100 \%$. Twenty-six parameters recorded during $\mathrm{HF}$ admission were used to predict TTR and TTD. To determine the parameter which mainly impacted TTR and TTD, variables were standardized, and effect size (ES) was calculated. Multivariate analysis by the AndersenGill model demonstrated that $\Delta L I R_{\text {admission }}(E S=0.72$ ), $\Delta \mathrm{LIR}_{\text {discharge }}(E S=-3.14)$, group assignment $(E S=0.2)$, maximal troponin during HF admission ( $E S=0.19)$, LVEF related to admission ( $E S=-0.22)$ and arterial hypertension ( $E S=$ $0.12)$ are independent predictors of TTR $\left(p<0.01, x^{2}=\right.$ $1,206)$. Analysis of ES showed that residual PC assessed by $\Delta \mathrm{LIR}_{\text {discharge }}$ was the most prominent predictor of TTR. One percent improvement in predischarge $P C$, assessed by $\Delta L R_{\text {discharge, }}$ was associated with a likelihood of $T T R$ increase by $14 \%$ (hazard ratio $[\mathrm{HR}] 1.14,95 \%$ confidence interval $[\mathrm{Cl}]$ $1.13-1.15, p<0.01)$ and TTD increase by $8 \%(\mathrm{HR} 1.08,95 \% \mathrm{Cl}$ 1.07-1.09, $p<0.01)$. Conclusion: The degree of predischarge $\mathrm{PC}$ assessed by $\triangle \mathrm{LIR}$ is the most dominant predictor of TTR and TTD.

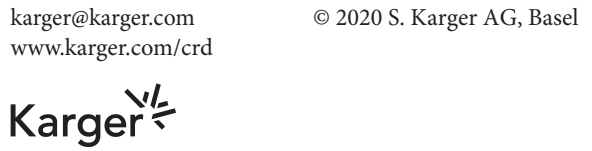

Michael Kleiner-Shochat

Heart Institute, Hillel Yaffe Medical Center POB 169

IS-38100 Hadera (Israel)

shochat1@gmail.com 


\section{Introduction}

Decompensated heart failure (HF) is a leading cause of rehospitalization among HF patients $[1,2]$. Predischarge pulmonary congestion (PC) seems to play a significant role in the evolution of this adverse outcome [3]. Hemodynamic monitoring, blood NT-proBNP (N-terminal probrain natriuretic peptide) levels, lung ultrasound (LUS), and lung impedance (LI) techniques have been previously proposed as alternative methods to assess PC [4-18].

In the IMPEDANCE-HF trial, $256 \mathrm{HF}$ patients were either assessed clinically or by LI guidance in an outpatient setting. Assessment of the lung fluid status by the impedance device was found to be effective. Preemptive LI-guided treatment resulted in fewer HF readmissions and lower HFassociated and all-cause mortality [17]. The IMPEDANCEHF trial was extended in order to answer the question of whether PC, assessed by LI, could improve risk stratification of readmission for HF in comparison with traditional methods. It also demonstrated that the difference between admission and discharge LI values $(\triangle \mathrm{PC})$, which represents the degree of improvement in PC during admission, was found to be a better predictor of clinical outcome than NT-proBNP [18]. However, some difficulties were observed with the use of $\triangle \mathrm{PC}$. In about $10 \%$ of patients, considerable improvement in $\triangle \mathrm{PC}$ did not necessarily reflect effective decongestion at discharge. In addition, measuring LI during the first hours following HF admission in order to calculate $\triangle \mathrm{PC}$ at discharge is difficult, especially if the patient is delayed in the emergency room. Therefore, we decided to evaluate $\Delta \mathrm{LIR}_{\text {discharge }}$ that requires 1 measurement at discharge in comparison with $\triangle \mathrm{PC}$ and other parameters measured during admission in order to select the best predictor of clinical outcome.

The aim of the present post hoc analysis of the IMPEDANCE-HF extended trial was to demonstrate that the assessment of predischarge PC by the impedance technique may reliably predict the time to readmission (TTR) and time to death (TTD), and that $\Delta \mathrm{LIR}_{\text {discharge }}$ is indeed a better predictor of TTR and TTD than the other parameters measured in the study. If so, $\Delta \mathrm{LIR}_{\text {discharge }}$ could guide the therapy of HF patients during admission and help to determine timing of discharge in order to reduce readmission.

\section{Methods}

The IMPEDANCE-HF extended trial was a randomized, controlled, 2-center, single-blinded trial. Patients were eligible for participation if they were older than 18 years, with a left ventricular ejection fraction (LVEF) $\leq 45 \%$ at New York Heart Association
(NYHA) functional class II-IV, and hospitalized for HF within the 12 months prior to recruitment (ClinicalTrials.gov NCT01315223). Exclusion criteria included implantation of a cardiac resynchronization device within 3 months of planned recruitment and estimated glomerular filtration rate $<30 \mathrm{~mL} / \mathrm{min} / 1.73 \mathrm{~m}^{2}$. Study patients were randomized 1:1 to LI-guided or conventional therapy. Patients were followed monthly in the outpatient clinics of participating hospitals. LI values were available to the treating physicians in the LI-guided patient group but not in the control group where therapeutic decisions were based on clinical assessment only. All patients provided written informed consent.

In the event of hospitalization due to HF, vital signs, jugular vein distention and the extent of leg edema (both assessed using a 5 -point scale), and level of lung rales (basilar, lower $1 / 3$ or $1 / 2$ lung field, or higher) were documented on admission and at discharge. In addition, oximetry, chest X-ray (CXR), NYHA class, creatinine, hemoglobin, sodium and potassium levels, the highest troponin value during admission, body mass index, as well as LI and NTproBNP (assessed within $16 \mathrm{~h}$ from admission and at discharge) were also recorded.

\section{Criteria for HF Hospitalization}

The cause of hospitalization was considered to be HF related if all of the following criteria were fulfilled: (1) the primary discharge diagnosis in the medical record was acute HF; (2) clinical signs indicating worsening HF such as increased dyspnea, peripheral edema, or jugular vein distention; weight gain $(\geq 1.5 \mathrm{~kg})$, or a change in NYHA class were present; and (3) increased PC assessed by CXR or an increase in the admission serum NT-proBNP versus the previous level. The event of all-cause death at home was accounted for in the TTD analysis. If the cause for admission or death was unclear, adjudication of the diagnosis (by chart review) was carried out by 2 independent cardiologists.

\section{Measurements}

The noninvasive impedance device (CardioSet Company, Tel Aviv, Israel) was used in this study to assess the lung fluid content. The normal "dry" LI (NLI) corresponding to normal lung fluid content for each patient was determined by a previously reported method [16], whose accuracy was validated by comparison with CXR ( $r=0.92, p<0.01$ between NYHA-related LI and CXR) [16]. Calculated NLI was used to compute the $\Delta$ LIR $=([$ measured $\mathrm{LI} / \mathrm{NLI}]-1) \times 100 \%$. $\Delta$ LIR represents the degree of instantaneous lung congestion compared to the normal lung fluid state. When pulmonary fluid content exceeds the normal level, the electrical resistance of the lung tissue decreases, and LI values decrease to lower levels than NLI, presenting $\Delta$ LIR as negative.

\section{Statistical Analysis}

Continuous variables are presented as means \pm SD if normally distributed according to the Kolmogorov-Smirnov and visual inspection tests or as medians and interquartile ranges if not. Categorical variables were analyzed by $\chi^{2}$ (Fisher) tests. Twenty-six variables recorded in the study were used for TTR and TTD analysis. Multivariate forward stepwise analysis utilized the AndersenGill modification of Cox regression analysis adopted for recurrent events with entrance criterion in the forward selection model when $p=0.05$ and $p=0.15$ for removal. Variables $\left(x_{i}^{*}\right)$ were standardized using mean $(m)$ and standard deviation $(\mathrm{sd})$ for reaching comparability of effect size (ES) of the different parameters as follows:
Kleiner-Shochat et al. 


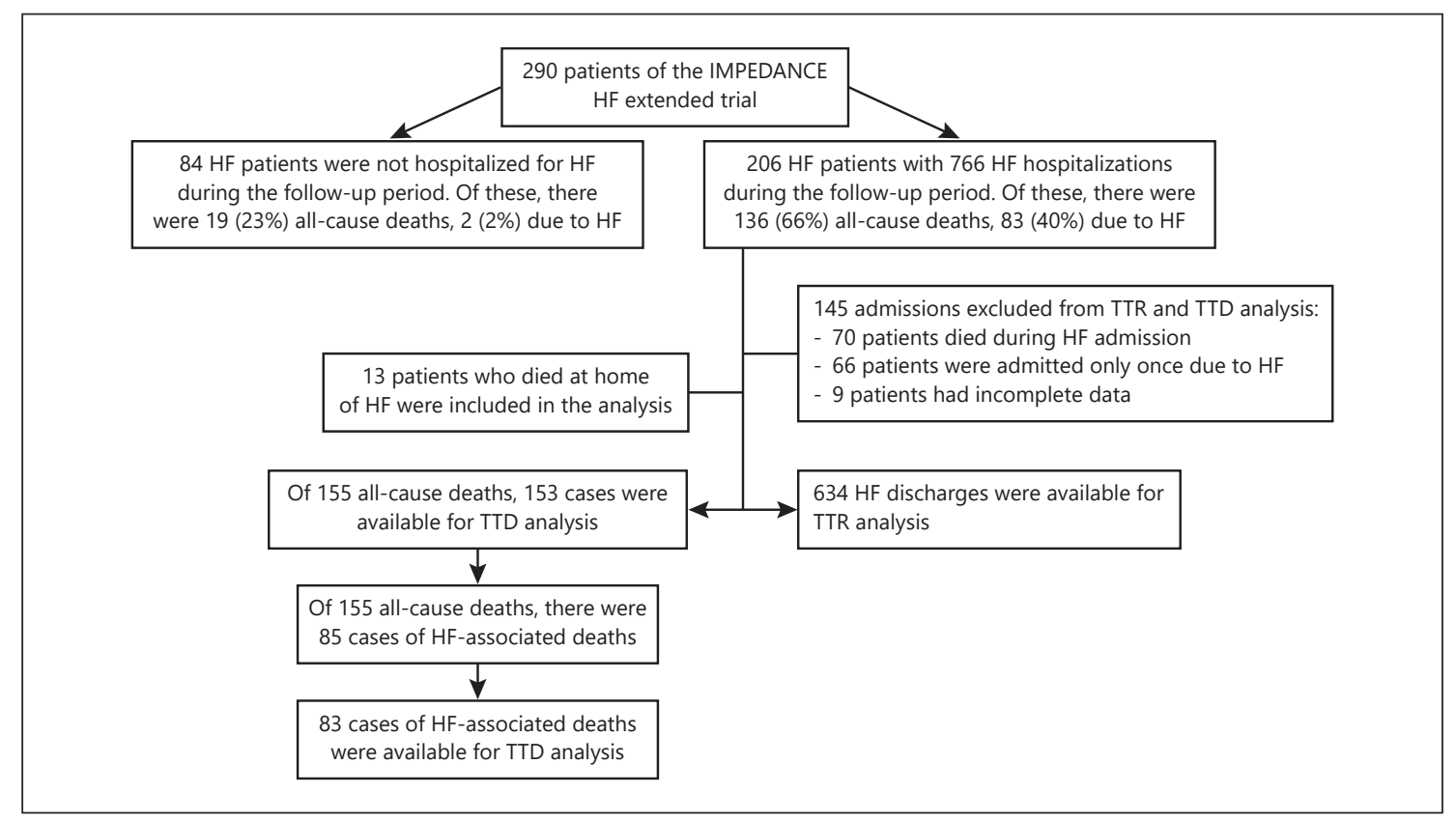

Fig. 1. Study flowchart.

$x_{i}^{*}=\left(x_{i}-m\right) /$ sd. Because of nonlinearity, NT-proBNP variables were logarithmically transformed. Adjusted hazard ratio (HR) and 95\% confidence intervals (CI) for postdischarge outcomes in study patients were calculated by LI and NT-proBNP level quartiles. Receiver-operating characteristic (ROC) curves were used to assess the discriminative capability of LI and NT-proBNP to predict clinical outcome. A value of $p<0.05$ was considered significant. The SPSS 21.0 statistical package, StatSoft Inc. (version 12) and the MedCalc statistical software (version 14.8.1) were used for statistical analysis.

\section{Results}

Two hundred and ninety HF patients participating in the IMPEDANCE-HF extended trial were randomized 1:1 to the LI-guided and control groups. The follow-up period of study patients was $57.2 \pm 39$ months. Of the 290 patients participating in the study, 84 were not hospitalized for HF, and 206 patients were admitted 766 times due to HF exacerbation (Fig. 1). During the follow-up, 155 patients died; 85 patients (55\%) died due to HF. For 634 HF hospitalizations, 153 all-cause deaths, and $85 \mathrm{HF}$-associated deaths, details were available for multivariate analysis required for the formulation of the model to predict TTR and TTD (Fig. 1). Table 1 presents demographic, clinical, and laboratory data of the study population. The impedance, clinical, and lab- oratory parameters related to HF admissions are shown in Table 2.

Seventy-eight patients in the LI-guided group completed the study follow-up (70.9 \pm 41 months) while 67 in this group died during follow-up (49.9 \pm 33 months), with an overall follow-up period in the LI-guided group of $61.2 \pm 40$ months. In the control group, the mean followup of 56 patients that remained alive at study completion lasted $70.5 \pm 38$ months while it was $42.3 \pm 38.1$ months in those who died during the follow-up, with an overall follow-up of $53.2 \pm 40.5$ months ( $p<0.01$ vs. LI group).

Univariate analysis of the association between the 26 variables recorded during $\mathrm{HF}$ admissions found 8 variables to be significantly related to TTR (online suppl. Table 1; see www.karger.com/doi/10.1159/000510073 for all online suppl. material).

Multivariate analysis revealed that only 6 variables independently predict TTR (Table 3). After standardization of all variables, $\Delta \mathrm{LIR}_{\text {discharge }}$ was found as the dominant predictor of TTR with an ES coefficient equal to 3.14, whereas ES of the other independent predictors varied between 0.12 and 0.72 (online suppl. Table 2). For $\Delta \operatorname{LIR}_{\text {discharge }}$ alone, $\chi^{2}$ was $1,062(p<0.01$, ) while the 6 -variable model yielded a $\chi^{2}$ of $1,206(p<0.01)$. A $1 \%$ decrease in $\Delta \mathrm{LIR}_{\text {discharge }}$ was also associated with a $14 \%$ probability increase in TTR (HR $0.86, p<0.01)$. The degree of PC on admission ( $\left.\Delta \mathrm{LIR}_{\mathrm{admission}}\right)$ was the second 
Table 1. Patient characteristics

\begin{tabular}{|c|c|c|}
\hline Variables & $\begin{array}{l}\text { Study entry } \\
(n=290)\end{array}$ & $\begin{array}{l}\text { First admission } \\
\text { for } \operatorname{HF}(n=206)\end{array}$ \\
\hline Age, years & $68.2 \pm 9.9$ & $69.8 \pm 10.7$ \\
\hline Male, $\%$ & 86 & 84 \\
\hline Left ventricular ejection fraction (IQR), \% & $30(25-35)$ & $30(14-35)$ \\
\hline \multicolumn{3}{|l|}{ NYHA class, $\%$} \\
\hline II & 46 & 30 \\
\hline III & 32 & 65 \\
\hline IV & 22 & 5 \\
\hline Ischemic etiology, $\%$ & 75 & 80 \\
\hline $\mathrm{S} / \mathrm{P}$ coronary artery bypass graft, $\%$ & 19 & 25 \\
\hline Atrial fibrillation/flutter, $\%$ & 26 & 34 \\
\hline Diabetes mellitus, $\%$ & 52 & 61 \\
\hline Hypertension, \% & 75 & 76 \\
\hline Hyperlipidemia, \% & 79 & 80 \\
\hline Chronic lung disease/bronchial asthma, \% & 5 & 4 \\
\hline Chronic renal failure, $\%$ & 35 & 36 \\
\hline Smoking, \% & 39 & 40 \\
\hline Implantable cardioverter defibrillator, $n(\%)$ & $83(29)$ & $62(30)$ \\
\hline CRT-D, $n(\%)$ & $107(40)$ & $84(41)$ \\
\hline \multicolumn{3}{|l|}{ Medication } \\
\hline ACEI or ARB, \% & 96 & 96 \\
\hline$\beta$-Blockers, $\%$ & 92 & 92 \\
\hline Mineralocorticoid receptor antagonist, \% & 74 & 73 \\
\hline Nitrates, $\%$ & 42 & 43 \\
\hline Statin, \% & 91 & 90 \\
\hline Aspirin, \% & 80 & 80 \\
\hline Digoxin, \% & 35 & 36 \\
\hline Diuretics \% & 97 & 100 \\
\hline Furosemide equivalent dose, mg/day & 103 & 117 \\
\hline Body mass index, $\mathrm{kg} / \mathrm{m}^{2}$ & $29.2 \pm 4.1$ & $29.3 \pm 5.1$ \\
\hline Systolic blood pressure, $\mathrm{mm} \mathrm{Hg}$ & $128 \pm 18$ & $125 \pm 17$ \\
\hline $\mathrm{JVD}^{1}$ & $0.8 \pm 0.7$ & $1.6 \pm 1.2$ \\
\hline Dyspnea on admission, \% & 93 & 95 \\
\hline Estimated glomerular filtration rate, $\mathrm{mL} / \mathrm{min} / 1.73 \mathrm{~m}^{2}$ & $61.2 \pm 18.9$ & $58.5 \pm 17.8$ \\
\hline
\end{tabular}

IQR, interquartile range; $n$, number of events; HF, heart failure; NYHA, New York Heart Association; CRT-D, cardiac resynchronization therapy-defibrillator; ACEI, angiotensin-converting enzyme inhibitor; ARB, angiotensin receptor blocker; $\mathrm{S} / \mathrm{P}$, status post. ${ }^{1}$ Jugular vein distention (JVD), 5 -point scale: JVD $=0$, means there is no JVD $>2 \mathrm{~cm}$ above the sternal notch; 4 , maximal distention.

most significant predictor of TTR (Table 3; online suppl. Table 2) with ES coefficient $=0.72 . \Delta \mathrm{PC}=$ $\left(\Delta \mathrm{LIR}_{\text {admission - discharge }}\right)$, which reflects the improvement in PC during admission, was not found to independently predict TTR.

Univariate analysis of the association between the evaluated parameters and TTD demonstrated that 5 parameters significantly impacted on TTD (online suppl. Table 3). Adjusted multivariate analysis of the variables evaluated as predictors of TTD demonstrated that 8 variables are independent predictors of TTD (Table 3). The most powerful predictor was $\Delta \operatorname{LIR}_{\text {discharge }}(p<0.01)$ according to standardized variable analysis (online suppl. Table 4). A $1 \%$ decrease in residual congestion at discharge corresponded to a likely increase in TTD by $8 \%$ (HR 1.08, 95\% CI 1.07-1.09, $p<0.01$ ).

\section{Discharge $\triangle L I R$ and NT-proBNP as Predictors of Outcome}

The values of $\Delta \mathrm{LIR}_{\text {discharge }}$ and log NT-proBNP $\mathrm{discharge}$ were stratified by quartiles (Table 2). TTR stratified by $\Delta \mathrm{LIR}_{\text {discharge }}$ and log NT-proBNP $\mathrm{discharge}_{\text {quartiles dem- }}$ 
Table 2. Parameters of patients $(n=206)$ hospitalized for heart failure (HF)

\begin{tabular}{|c|c|}
\hline Age at HF discharge, years & $72.3 \pm 11.2$ \\
\hline Left ventricular ejection fraction related to $\mathrm{HF}$ admission & $26.7 \pm 6.3 \%$ \\
\hline$\Delta \mathrm{LIR}_{\text {admission }} / \Delta \mathrm{LIR}_{\text {discharge }}$ & $-46.5 \pm 8.6 /-32.9 \pm 13.4 \%$ \\
\hline \multicolumn{2}{|l|}{$\Delta \mathrm{LIR}_{\text {discharge }}$} \\
\hline Quartile 1 & 0 to $-21.7 \%$ \\
\hline Quartile 2 & -21.8 to $-32.2 \%$ \\
\hline Quartile 3 & -32.3 to $-41.1 \%$ \\
\hline Quartile 4 & -41.2 to $-73.0 \%$ \\
\hline \multicolumn{2}{|l|}{ Median NT-proBNP (IQR), pg/mL } \\
\hline On admission & $11,467(8,930-14,700)$ \\
\hline At discharge & $6,800(4,784-9,200)$ \\
\hline \multicolumn{2}{|l|}{ NT-proBNP discharge } \\
\hline Quartile 1 & $<4,789$ \\
\hline Quartile 2 & $4,790-6,800$ \\
\hline Quartile 3 & $6,801-9,200$ \\
\hline Quartile 4 & $>9,200$ \\
\hline \multicolumn{2}{|l|}{ Median NYHA (IQR) } \\
\hline On admission & $4.0(3.0-4.0)$ \\
\hline At discharge & $3.0(2.0-3.0)$ \\
\hline \multicolumn{2}{|l|}{ Median jugular vein distention (IQR) } \\
\hline On admission & $3.0(2.0-3.0)$ \\
\hline At discharge & $2.0(1.0-3.0)$ \\
\hline Length of hospital stay, days & $5.2 \pm 3.9$ \\
\hline Creatinine $_{\text {admission/discharge }}, \mathrm{mg} / \mathrm{dL}$ & $1.6 \pm 0.6 / 1.7 \pm 0.7$ \\
\hline Hemoglobin $_{\text {discharge, }} \mathrm{g} / \mathrm{dL}$ & $12.1 \pm 1.6$ \\
\hline Sodium $_{\text {discharge }}, \mathrm{mmol} / \mathrm{L}$ & $138.0 \pm 4.0$ \\
\hline Potassium $_{\text {discharge }}, \mathrm{mmol} / \mathrm{L}$ & $4.4 \pm 0.6$ \\
\hline Troponin (highest value during HF admission), ng/mL & $69 \pm 66$ \\
\hline Post-HF discharge 30 -day/1-year rate of HF readmission, \% & $33 / 79$ \\
\hline \multicolumn{2}{|l|}{ Distribution according quartiles $1-4$ of $\Delta \mathrm{LIR}, \%$} \\
\hline 30-day HF readmission & $0: 3: 29: 68$ \\
\hline 1-year HF readmission & $4: 30: 32: 34$ \\
\hline 30-day HF death & 0:0:0:100 \\
\hline 1-year HF death & $3: 23: 26: 48$ \\
\hline 30-day all-cause death & 0:0:0:100 \\
\hline 1-year all-cause death & $6: 28: 27: 39$ \\
\hline \multicolumn{2}{|l|}{ Distribution according quartiles $1-4$ of NT-proBNP, $\%$} \\
\hline 30-day HF readmission & $3: 8: 23: 66$ \\
\hline 1-year HF readmission & $16: 19: 27: 38$ \\
\hline 30-day HF death & $0: 8: 19: 73$ \\
\hline 1-year HF death & $8: 17: 29: 46$ \\
\hline 30-day all-cause death & $3: 18: 18: 61$ \\
\hline 1-year all-cause death & $14: 23: 27: 36$ \\
\hline Post-HF discharge 30-day/1-year rate of HF death, \% & $4: 10$ \\
\hline Furosemide dose/day of hospital stay, mg & $122 \pm 28$ \\
\hline
\end{tabular}

$\Delta \mathrm{LIR}$, lung impedance ratio; NT-proBNP, N-terminal probrain natriuretic peptide.

onstrated a strong association between the degree of PC at discharge and TTR (Fig. 2; $p<0.01$ ).

The probability of HF readmission and of all-cause mortality within 30 days/1 year was compared between patients who achieved optimal decongestion $\left(\mathrm{Q}_{1}\right)$ and those discharged with mild, moderate, and moderate-to- severe residual congestion $\left(\mathrm{Q}_{2-4}\right)$. This analysis indicated that residual PC assessed by $\Delta \mathrm{LIR}_{\text {discharge }}$ and $\log \mathrm{NT}$ -

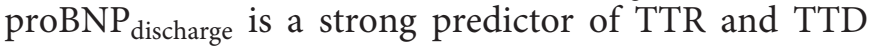
(Fig. 3a-d).

ROC analysis assessing the accuracy of $\triangle \mathrm{LIR}_{\text {discharge }}$ to predict rehospitalizations yielded an AUC of 0.93 for 30- 


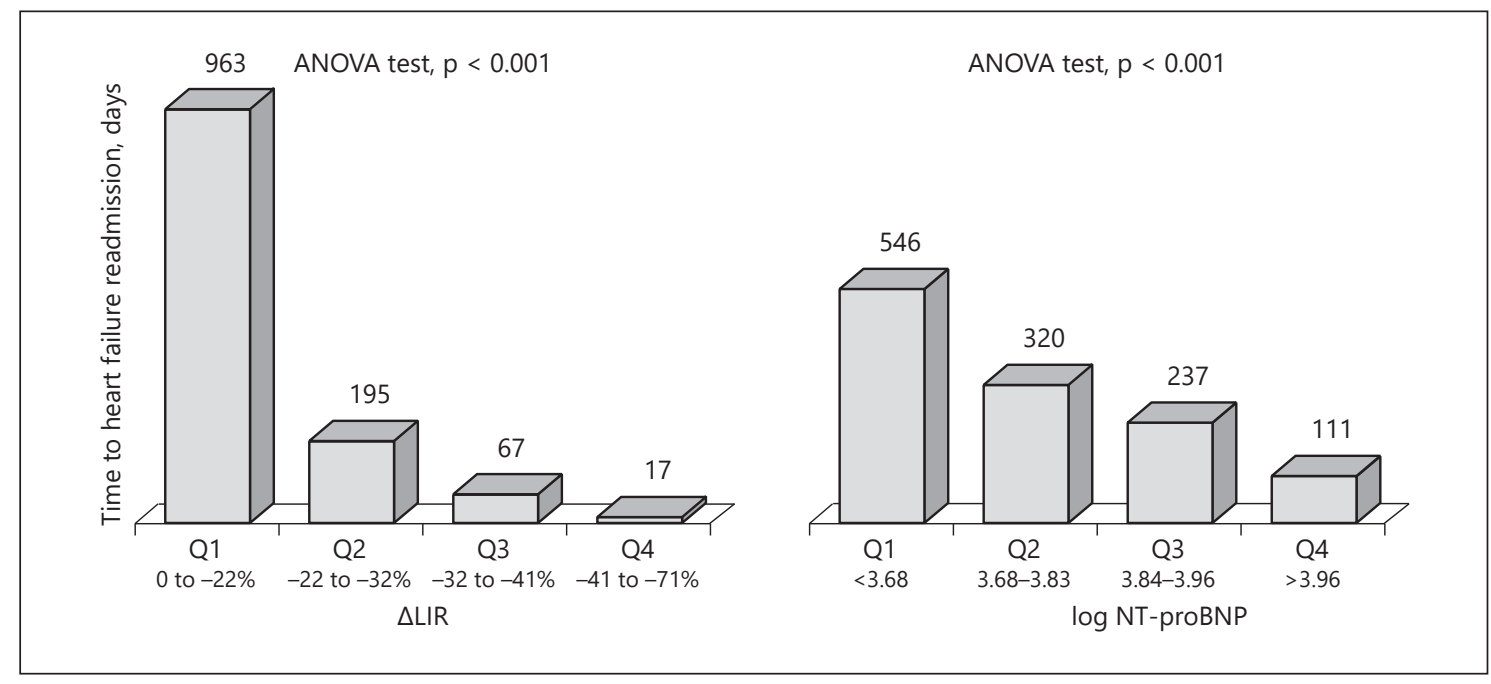

Fig. 2. Time to heart failure readmission: assessment of the pulmonary congestion at discharge by lung impedance $(\triangle \mathrm{LIR})$ compared with log NT-proBNP allows better discrimination of the times to readmission.

Table 3. Multivariate stepwise models predicting unplanned heart failure (HF) hospitalizations and all-cause death

\begin{tabular}{|c|c|c|c|}
\hline Impact of independent variables in multivariate stepwise models & HR & $95 \% \mathrm{CI}$ & $x^{2}$ \\
\hline \multicolumn{4}{|l|}{ Likelihood of TTR prolongation $(n=634)$} \\
\hline LI-guided vs. control group & 1.22 & $1.06-1.42$ & 7.15 \\
\hline$\Delta \operatorname{LIR}_{\text {admission }}($ decrease of $1 \%)$ & 1.06 & $1.05-1.08$ & 104 \\
\hline$\Delta \mathrm{LIR}_{\text {discharge }}($ decrease of $1 \%)$ & 1.14 & $1.13-1.15$ & 1,062 \\
\hline Maximal troponin (decrease of $100 \mathrm{ng} / \mathrm{ml}$ ) & 6.81 & $2.90-16.3$ & 19.3 \\
\hline Left ventricular ejection fraction (increase of $1 \%$ ) & 1.02 & $1.01-1.03$ & 8.7 \\
\hline Arterial hypertension (absent) & 1.23 & $1.03-1.48$ & 5.0 \\
\hline \multicolumn{4}{|l|}{ Likelihood of TTD prolongation $(n=153)$} \\
\hline Age (decrease of 1 year) & 1.03 & $1.01-1.05$ & 12.5 \\
\hline$\Delta \operatorname{LIR}_{\text {discharge }}($ decrease of $1 \%)$ & 1.08 & $1.07-1.09$ & 134 \\
\hline $\log$ NT-proBNP ${ }_{\text {admission - discharge (increase of } 1 \text { unit) }}$ & 1.72 & $1.08-2.86$ & 4.70 \\
\hline$J V D_{\text {admission }}-J_{V D}$ discharge (increase of 1 point) & 1.39 & $1.08-1.79$ & 6.10 \\
\hline Creatinine $_{\text {admission }}($ decrease of $0.1 \mathrm{mg} / \mathrm{dL})$ & 1.38 & $1.10-1.72$ & 7.90 \\
\hline Maximal troponin (decrease of $100 \mathrm{ng} / \mathrm{mL}$ ) & 11.5 & $1.39-94.9$ & 5.12 \\
\hline $\mathrm{Na}_{\text {discharge }}$ (increase of $1 \mathrm{mmol} / \mathrm{L}$ ) & 1.04 & $1.01-1.08$ & 5.59 \\
\hline Left ventricular ejection fraction (increase of $1 \%$ ) & 1.03 & $1.01-1.06$ & 4.86 \\
\hline
\end{tabular}

TTR, time to readmission; TTD, time to death; $\chi^{2}$, chi square test; $n$, the number of events; CI, confidence interval. Other abbreviations as in Tables 1 and 2 . All hazard ratios (HR) are statistically significant, $p<0.03$.

day readmissions due to HF and 0.97 for 1-year readmissions. Levels of $\log \mathrm{NT}$-proBNP discharge for prediction of HF readmission yielded AUC values of 0.68 and 0.62 for the 30-day and 1-year readmission, respectively (Fig. 4a, b). The AUC for 30-day all-cause mortality was 0.90 by the $\Delta \mathrm{LIR}_{\text {discharge }}$ and 0.80 for $\log \mathrm{NT}$-proBNP $\mathrm{discharge}_{\text {, }}$ and the AUC for the 1-year all-cause mortality was 0.89 and 0.73 for $\Delta \mathrm{LIR}_{\text {discharge }}$ and log NT-proBNP $\mathrm{discharge}_{\text {, }}$ respectively (Fig. 4c, d). PC assessed by $\Delta \mathrm{LIR}_{\text {discharge }}$ was found to be a better predictor of TTR and TTD than NTproBNP discharge $_{\text {at all time points }(}(p<0.05)$. 


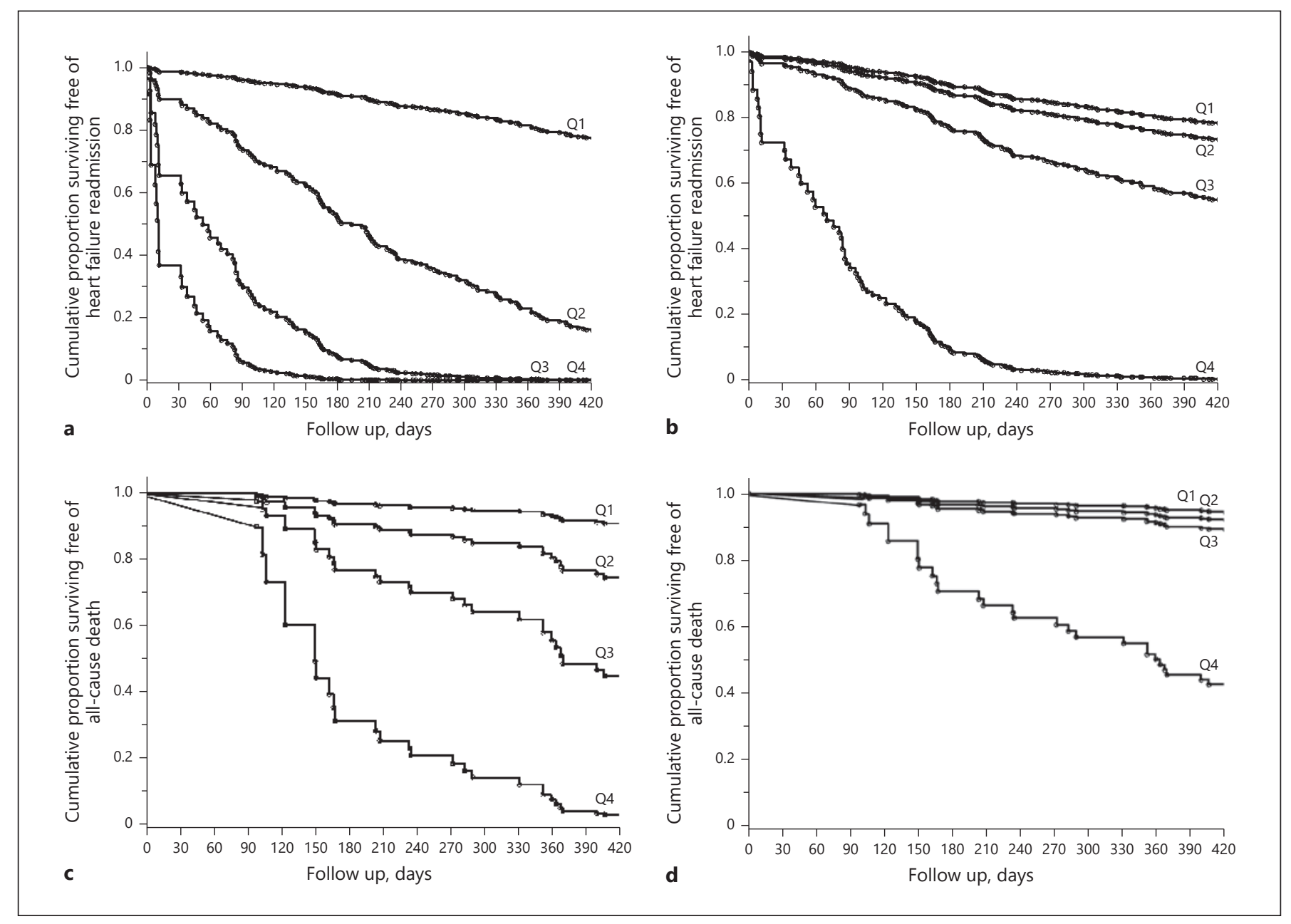

Fig. 3. Event-free 30-day and 1-year heart failure (HF) readmission and all-cause mortality stratified by lung impedance ratio ( $\triangle$ LIR) and NT-proBNP quartiles (Q1-Q4). a Risk of HF readmission stratified by $\triangle$ LIR. Hazard ratio (HR) and $95 \%$ confidence interval (CI). Q2/Q1: 7.1 (5.7-8.8), $p<0.01$; Q3/Q1: 28.1 (22.5-35.2), $p<$ 0.01; Q4/Q1: 66.4 (50.3-87.5), $p<0.01$. b Risk of HF readmission stratified by NT-proBNP. Q2/Q1: $1.3(0.9-1.7), p=0.15$; Q3/Q1:

\section{Discussion}

Using multivariate stepwise analysis of data from the IMPEDANCE-HF extended trial, $\triangle \mathrm{LIR}_{\text {discharge }}$ was shown to be the most prominent independent predictor of TTR and TTD while $\triangle$ PC did not predict outcome.

Prediction of readmission due to worsening HF was attempted using LUS and NT-proBNP levels [4-8, 10$12]$. LUS was found to be effective in predicting shortand long-term outcome in HF patients and showed good prognostic accuracy related to HF readmissions within 180 days [7]. However, LUS is operator dependent and
$2.5(1.7-3.5), p<0.01$; Q4/Q1: $22(12-40), p<0.01$. c Risk of allcause death stratified by $\Delta$ LIR. Q2/Q1: $3.1(2.1-4.7), p<0.01$; Q3/Q1: 8.5 (5.4-13.4), $p<0.01$; Q4/Q1: $37.7(23.2-61.1), p<0.01$. d Risk of all-cause death stratified by NT-proBNP. Q2/Q1: 1.5 (0.9-2.4), $p=0.12$; Q3/Q1: $2.1(1.2-3.5), p<0.01 ; \mathrm{Q} 4 / \mathrm{Q} 1: 15.6$ (7.5-32), $p<0.01$.

expensive. NT-proBNP is the most widely used parameter for outcome stratification in HF, with the contention that the discharge NT-proBNP had the best performance in predicting 1-year mortality or HF readmissions [11]. Therefore, in the present study, it was particularly important to compare the predictive accuracy of NT-proBNP levels with the LI method. Multivariate analysis demonstrated that if discharge $\triangle$ LIR was used for risk stratification, then the NT-proBNP level was no longer an independent predictor.

This result is especially important since the noninvasive LI technique has certain potential advantages. First, 


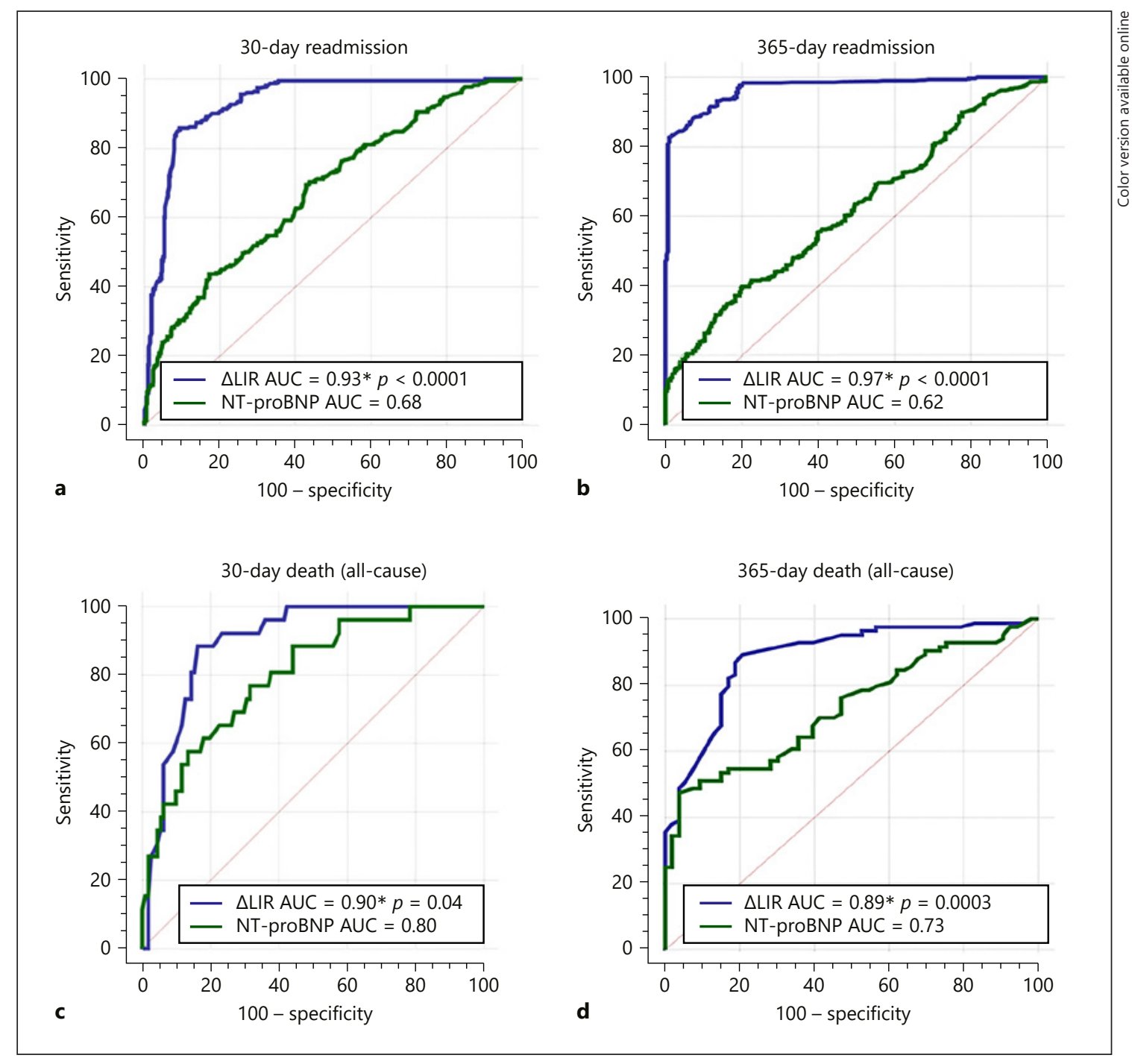

Fig. 4. a-d Receiver-operating curve analysis assessing the accuracy of the lung impedance ratio $\left(\Delta \operatorname{LIR}_{\text {discharge }}\right)$ and $\log$ NT-proBNP to predict 30-day and 1-year rehospitalizations. Prediction by $\triangle \mathrm{LIR}_{\text {discharge }}$ is more accurate

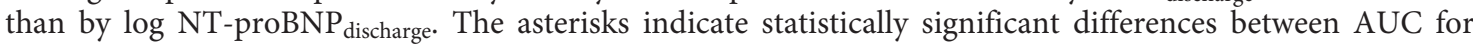
$\triangle \mathrm{LIR}_{\text {discharge }}$ and NT-proBNP discharge.

$\triangle$ LIR directly reflects the degree of PC, which is the primary cause of HF deterioration. Second, NT-proBNP is affected by concomitant disease and physiologic stressors [19], while $\Delta$ LIR has no such interaction. Third, $\Delta$ LIR is cheap and noninvasive requiring $<1 \mathrm{~min}$ to perform with an intra- and inter-variability of $<2 \%$.

The impedance technique has been introduced in the early 1980s and was used as a tool for measuring and monitoring $\mathrm{PC}$ for many years. The impedance technique is a simple method for monitoring PC, but its clinical efficacy was unproven for many years. A feasible explana- tion is that the traditional impedance technique measured the impedance of the entire chest (transthoracic impedance), which is 10-fold larger than LI which is the signal of interest (Fig. 5). Thus, the signal from the surrounding chest wall tissue (the noise signal) masked the minor lung tissue signal and thus precluded precise assessment of the lung fluid content.

In the basic paper, noninvasive transthoracic impedance was used for risk stratification of HF decompensation [20]. This study found that the technique was effective for prediction of short-term HF deterioration but 


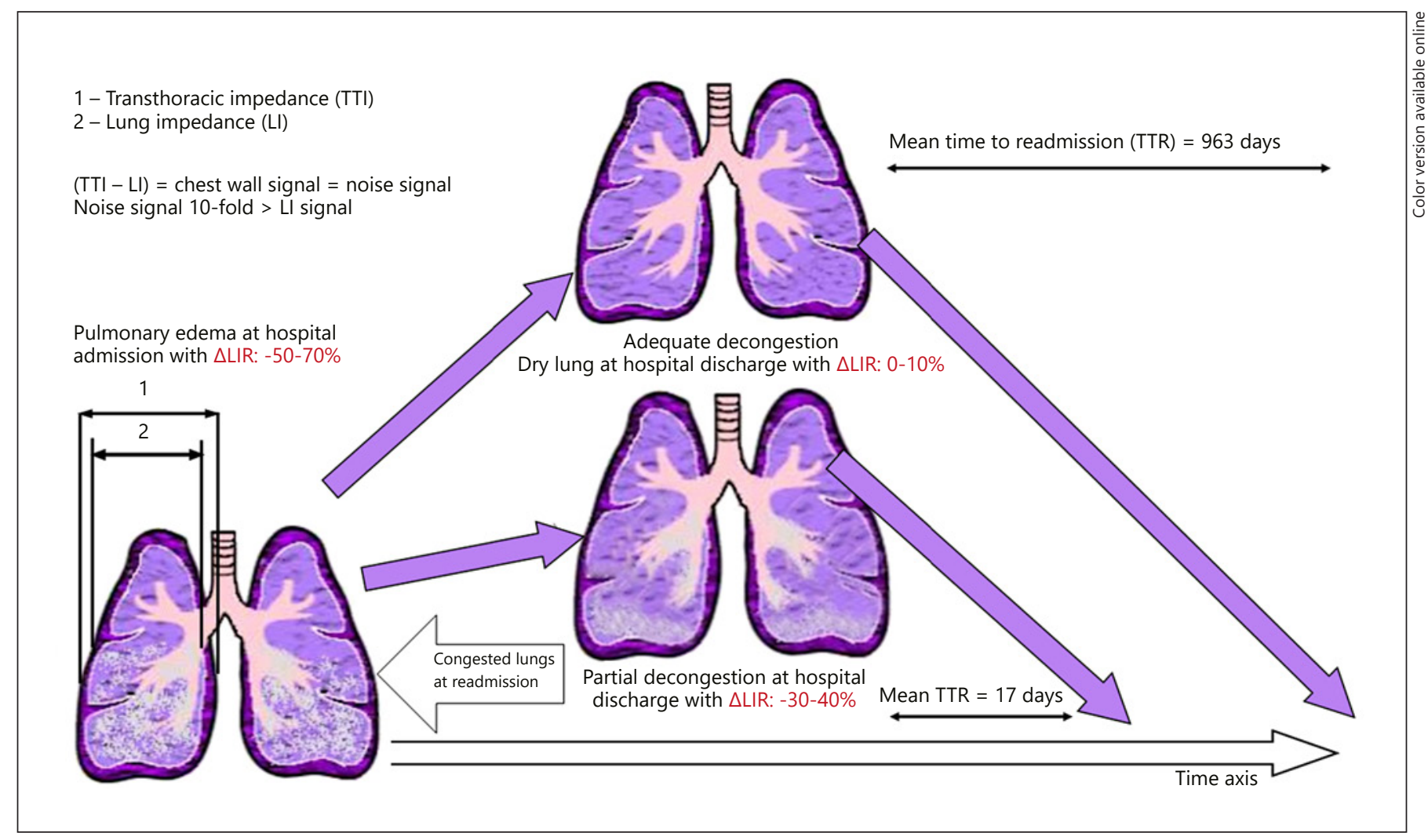

Fig. 5. Evolution of the pulmonary edema during hospital admission.

could not predict long-term HF exacerbation. Hence, the technique enabled to differentiate between patients with high and low risk to develop HF decompensation, but it was insensitive to determine the status of the PC of the individual patient. An explanation of this finding is that the measured transthoracic impedance reflects the resistance of the entire chest which is about 10-fold larger than LI, which reflects the fluid content of the lung. The device used in the present study utilizes an algorithm that calculates the impedance of the lung parenchyma by measuring total chest wall resistance and subtracting chest wall resistance.

Via incorporating LI measurement, the algorithm of implantable pacemakers was an attempt to substitute intrathoracic fluid measurement for the relatively low sensitive transthoracic signal. However, intrathoracic impedance measurements by the implantable devices did not improve outcome or decrease HF hospitalizations and outpatient visits in HF patients [21]. Charles et al. [22] have described the reasons for the limited effectiveness of these devices. The device used in the IMPED-
ANCE-HF trial is capable of differentiating the LI signal from the noise signal and, therefore, allows more reliable assessment of lung fluid, leading to impedance-guided therapy. This may be a possible explanation of the high efficacy of the new impedance technique in the IMPEDANCE-HF trial [17] for preventing HF readmissions and reliable assessment of predischarge PC in the IMPEDANCE-HF extended trial [18].

The practical implication of the present analysis is that measurement of $\triangle$ LIR at discharge following hospitalization for HF worsening could allocate patients into groups at low and high risk for 30-day readmission and death. The current analysis demonstrated an increased and unacceptable rate of HF readmissions and death in patients discharged with higher $P C$ quartiles $\left(\mathrm{Q}_{3-4}\right)$. A feasible explanation of the large proportion of patients discharged with significant residual congestion is the absence of clinical tools to adequately assess the extent of lung fluid overload and the pressure of insurers to discharge HF patients early, or, alternatively, that patients with advanced HF may demonstrate only minimal response to medical 
therapy. However, this does not indicate that more effective decongestion cannot be achieved in these patients. We found that about a third of HF patients discharged with inadequate decongestion $\left(\mathrm{Q}_{4}\right)$ achieved better decongestion during their next HF admission.

\section{Limitations}

The present study was a single-blinded, 2-center trial designed to assess the impact of LI guidance on the longterm management of patients with clinically significant HF treated in the hospital and followed-up in the outpatient clinic. Therefore, there was a potential bias in the decision of readmission in the LI-guided group. However, according to the protocol, the investigators were not involved throughout the trial in clinical decisions regarding inhospital treatment or the timing of discharge, while patient group assignment was unknown to in-house treating physicians. Hence, crossover interaction was practically impossible and possible bias minimized. In addition, approximately $9 \%$ of all-cause hospitalizations of study patients occurred in hospitals not participating in the study, so their data were not available.

\section{Conclusions}

Of 26 variables evaluated, $\mathrm{PC}$ at discharge, assessed by $\triangle \mathrm{LIR}$, was the best predictor of TTR and TTD. Residual congestion measured by LI at discharge was associated with an increased readmission rate and death.

\section{Acknowledgment}

We thank Nadia Bordo (MSc), Faculty of Industrial Engineering and Management, Technion - Israel Institute of Technology for statistical analysis, Haifa, Israel, and Sharon Daniel (MD, MPH, $\mathrm{PhD}$ ), Department of Public Health and Pediatrics, Faculty of Health Sciences, Soroka University Medical Center, Ben-Gurion University of Negev, Beersheba, Israel.

\section{Statement of Ethics}

The study protocol was approved by the local IRB (HYMC0002-13 and SOR 0284-13) and ClinicalTrials.gov NCT01315223. All patients provided written informed consent.

\section{Conflict of Interest Statement}

M.K.S. is a member of the board of directors of the CardioSet Startup Company, the manufacturer and supplier of the devices used in the trial.

\section{Funding Sources}

The study was not funded by any external source. The monitors used in the study were provided by CardioSet Ltd.

\section{Author Contributions}

M.K.S. and S.M. contributed to the conception, study design, analysis, interpretation of data, and final approval, while all other authors were involved in the interpretation of data and final approval.

\section{References}

1 Krumholz HM, Lin Z, Keenan PS, Chen J, Ross JS, Drye EE, et al. Relationship between hospital readmission and mortality rates for patients hospitalized with acute myocardial infarction, heart failure, or pneumonia. JAMA. 2013 Feb;309(6):587-93.

2 Jencks SF, Williams MV, Coleman EA. Rehospitalizations among patients in the Medicare fee-for-service program. N Engl J Med. 2009 Apr;360(14):1418-28.

3 Guglin M. Key role of congestion in natural history of heart failure. Int J Gen Med. 2011; 4:585-91.

4 Coiro S, Rossignol P, Ambrosio G, Carluccio E, Alunni G, Murrone A, et al. Prognostic value of residual pulmonary congestion at discharge assessed by lung ultrasound imaging in heart failure. Eur J Heart Fail. 2015 Nov; 17(11):1172-81.
5 Gargani L, Pang PS, Frassi F, Miglioranza $\mathrm{MH}$, Dini FL, Landi P, et al. Persistent pulmonary congestion before discharge predicts rehospitalization in heart failure: a lung ultrasound study. Cardiovasc Ultrasound. 2015 Sep;13(1):40.

6 Donadio C, Bozzoli L, Colombini E, Pisanu G, Ricchiuti G, Picano E, et al. Effective and timely evaluation of pulmonary congestion: qualitative comparison between lung ultrasound and thoracic bioelectrical impedance in maintenance hemodialysis patients. Medicine (Baltimore). 2015 Feb;94(6):e473.

7 Platz E, Campbell RT, Claggett B, Lewis EF, Groarke JD, Docherty KF, et al. Lung ultrasound in acute heart failure: prevalence of pulmonary congestion and short- and longterm outcomes. JACC Heart Fail. 2019 Oct; 7(10):849-58.
8 O'Connor CM, Hasselblad V, Mehta RH, Tasissa G, Califf RM, Fiuzat M, et al. Triage after hospitalization with advanced heart failure: the ESCAPE (Evaluation Study of Congestive Heart Failure and Pulmonary Artery Catheterization Effectiveness) risk model and discharge score. J Am Coll Cardiol. 2010 Mar; 55(9):872-8.

9 Abraham WT, Adamson PB, Bourge RC, Aaron MF, Costanzo MR, Stevenson LW, et al; CHAMPION Trial Study Group. Wireless pulmonary artery haemodynamic monitoring in chronic heart failure: a randomised controlled trial. Lancet. 2011 Feb;377(9766): 658-66. 
10 Noveanu M, Breidthardt T, Potocki M, Reichlin T, Twerenbold R, Uthoff $\mathrm{H}$, et al. Direct comparison of serial B-type natriuretic peptide and NT-proBNP levels for prediction of short- and long-term outcome in acute decompensated heart failure. Crit Care. 2011; 15(1):R1.

11 Kociol RD, Horton JR, Fonarow GC, Reyes EM, Shaw LK, O'Connor CM, et al. Admission, discharge, or change in B-type natriuretic peptide and long-term outcomes: data from Organized Program to Initiate Lifesaving Treatment in Hospitalized Patients with Heart Failure (OPTIMIZE-HF) linked to Medicare claims. Circ Heart Fail. 2011 Sep; 4(5):628-36.

12 Demissei BG, Postmus D, Cleland JG, O'Connor CM, Metra M, Ponikowski P, et al. Plasma biomarkers to predict or rule out early post-discharge events after hospitalization for acute heart failure. Eur J Heart Fail. 2017 Jun;19(6):728-38.

13 Simpson J, Jhund P, Lund L, Padmanabhan S, Claggett BL, Shen L, et al. Prognostic Models Derived in PARADIGM-HF and Validated in ATMOSPHERE and the Swedish Heart Failure Registry to Predict Mortality and Morbidity in Chronic Heart Failure. JAMA Cardiol. 2020 Jan;5(4):432-41.
14 Shochat M, Shotan A, Blondheim DS, Kazatsker M, Dahan I, Asif A, et al. Usefulness of lung impedance-guided pre-emptive therapy to prevent pulmonary edema during STelevation myocardial infarction and to improve long-term outcomes. Am J Cardiol. 2012 Jul;110(2):190-6.

15 Shochat M, Shotan A, Trachtengerts V, Blondheim DS, Kazatsker M, Gurovich V, et al. A novel radiological score to assess lung fluid content during evolving acute heart failure in the course of acute myocardial infarction. Acute Card Care. 2011 Jun;13(2):81-6.

16 Shochat M, Shotan A, Blondheim DS, Kazatsker M, Dahan I, Asif A, et al. Derivation of baseline lung impedance in chronic heart failure patients: use for monitoring pulmonary congestion and predicting admissions for decompensation. J Clin Monit Comput. 2015 Jun;29(3):341-9.

17 Shochat MK, Shotan A, Blondheim DS, Kazatsker M, Dahan I, Asif A, et al. Non-Invasive Lung IMPEDANCE-Guided Preemptive Treatment in Chronic Heart Failure Patients: A Randomized Controlled Trial (IMPEDANCE-HF Trial). J Card Fail. 2016 Sep;22(9): $713-22$.

18 Kleiner Shochat M, Fudim M, Shotan A, Blondheim DS, Kazatsker M, Dahan I, et al. Prediction of readmissions and mortality in patients with heart failure: lessons from the IMPEDANCE-HF extended trial. ESC Heart Fail. 2018 Oct;5(5):788-99.
19 Meijers WC, van der Velde AR, Muller Kobold AC, Dijck-Brouwer J, Wu AH, Jaffe A, et al. Variability of biomarkers in patients with chronic heart failure and healthy controls. Eur J Heart Fail. 2017 Mar; 19(3):357-65.

20 Packer M, Abraham WT, Mehra MR, Yancy CW, Lawless CE, Mitchell JE, et al; Prospective Evaluation and Identification of Cardiac Decompensation by ICG Test (PREDICT) Study Investigators and Coordinators. Utility of impedance cardiography for the identification of short-term risk of clinical decompensation in stable patients with chronic heart failure. J Am Coll Cardiol. 2006 Jun;47(11): 2245-52.

21 van Veldhuisen DJ, Braunschweig F, Conraads V, Ford I, Cowie MR, Jondeau G, et al; DOT-HF Investigators. Intrathoracic impedance monitoring, audible patient alerts, and outcome in patients with heart failure. Circulation. 2011 Oct;124(16):1719-26.

22 Charles CJ, Rademaker MT, Melton IC, Gutfinger D, Eigler NL, Qu F, et al. Thoracic impedance measures tissue characteristics in the vicinity of the electrodes, not intervening lung water: implications for heart failure monitoring. J Clin Monit Comput. 2015 Feb;29(1): 65-76. 